\title{
EL CATALÀ I ALTRES LLENGÜES EN CONCURRÈNCIA A LA CORT I A LA CANCELLERIA NAPOLITANES D'ALFONS EL MAGNÀNIM (1443-1458)*
}

\author{
CATALAN AND OTHER LANGUAGES IN CONTACT IN \\ THE COURT AND IN THE CHANCELLERY IN NAPLES OF \\ ALFONSO THE MAGNANIMOUS (1443-1458)
}

\author{
Abel Soler \\ Universitat de València \\ abel.soler@uv.es
}

Resum: El trasllat de la cort del rei Alfons V d'Aragó de València (I4I6-I430) a Itàlia (I432) i la seua instal-lació a Nàpols (I443-I458) comportaren l'emigració d'un nombrós col-lectiu humà, percebut dualment per la població napolitana (catalani et hispani: catalanoparlants i castellanoparlants), i d'una administració reial on el català era la llengua preferida de govern i d'estat, per bé que el rei s'expressara normalment en castellà. El nombrós col-lectiu cortesà, sesquilingüe en molts casos, participava —d'una manera o altra—d'una pluralitat d'expressions lingüístiques, orals i escrites: buròcrates i cavallers majoritàriament valencians; poetes de cançoner castellans; humanistes que redactaven en un llatí primmirat; barons nadius que s'expressaven en un napoletano misto, influït pel toscà literari; escrivans de la cancelleria que redactaven en sicilià, mercaders florentins, etc. Tot plegat, fa de la cort napolitana d'Alfons el Magnànim un objecte d'estudi molt interessant per al camp de la història de la llengua (deixant de banda ara la vehiculació idiomàtica de les expressions literàries, un aspecte que també mereix ser estudiat).

Paraules clau: història de la llengua catalana, cancelleria reial, Alfons el Magnànim, Nàpols.

Abstract: The move of the court of the king Alfonso V of Aragon from Valencia (I4I6-I430) to Italy (I432) and their settlement in Naples (I443-I458) implied the emigration of a numerous human group, which was perceived as a duality by the Neapolitans (catalani et hispani: Catalan speaking people and Spanish speaking people), and also a royal administration where Catalan was the

(*) Aquest article és un extracte de la part introductòria de la nostra tesi doctoral (Soler 20I7 [2016]), a la qual us remetem per a més detalls. 
Abel Soler

El català $i$ altres llengües en concurrència a la cort $i$

a la cancelleria napolitanes d'Alfons el Magnànim (1443-I458)

preferred language by the government and state, even though the king used to speak in Spanish. The numerous court, who was almost bilingual in most cases, was involved -in greater or lesser proportion - in a plurality of linguistic expressions, both orally and written: there were bureaucrats and knights mainly from Valencia; Castilian song poets; humanists who used to write in perfect Latin; native barons who spoke in a napoletano misto, influenced by the literary Tuscan; scriveners from the chancery who wrote in Sicilian dialect, merchants from Florence, etc. Altogether, this makes the court in Naples of Alfonso the Magnanimous a very interesting object of study for the field of the history of the language (leaving aside now the idiomatic adaptation of the literary expressions, being also an aspect that deserves to be studied).

Key words: history of Catalan language, royal chancery, Alfonso the Magnanimous, Naples.

es es es

\section{L'EMPRESA ITALIANA I EL TRASLLAT DE LA CORT DE VALĖNCIA A NÀPOLS}

Alfonso de Trastámara y Alburquerque (Medina del Campo, I396 - Nàpols, I458), més conegut com Alfons V el Magnànim, rei d'Aragó (I4I6-I458), I de Nàpols (I443I458), tingué cort preferentment al Palau del Real de València en els primers anys del regnat (I4I6-I43O), tret d'un parèntesi mediterrani (I420-I423), on es frustraren les seues expectatives d'instal-lar-se a Nàpols i esdevenir el successor de la reina Joana II d'Anjou-Durazzo. Preparada una nova expedició mediterrània pels anys I430-I432, el rei i la seua cort es desplaçaren a Sicília (I432-I435) i Gaeta (I436-I443), i portaren a terme la guerra de conquesta de Nàpols (I436-I443). El rei d'Aragó començà a assumir llavors el seu paper de Rex Italicus - expressió que encara es llig en l'arc de triomf del Castell Nou de Nàpols_ — i s'instal-là definitivament amb els seus a Itàlia.

La renovada cort, establida triomfalment a Nàpols l'any I443, ho feia en una metròpoli de 60.000 habitants, majoritàriament parlants dela llengua o dialetto napolità. Abans de l'arribada dels cancellers hispànics, la documentació oficial s'havia redactat solament en llatí. ${ }^{1}$ Les elits socials i culturals —una ínfima minoria—solien usar una mena de koiné toscaneggiante per a comunicar-se per escrit amb la resta d'Itàlia. Els nadius residents a la cort escrivien — i procuraven parlar- el napoletano misto: una versió refinada de la parla popular, influïda pel lèxic i les solucions gramaticals de la

I.Segons Palmieri (2006: I29), a la cancelleria reial de Nàpols, sota domini francés, «furono redatti atti pubblici esclusivamente in latino e fino a tutta l'età di Giovanna II compresa.» 
literatura toscana del Trecento. ${ }^{2} \mathrm{El}$ rei nouvingut, un «estranger», era castellà «de nació», com una part dels seus exèrcits i cortesans. No obstant això, el gros del cos nobiliari i de l'aparell administratiu — la Cancelleria, una majoria de cavallers - s'expressava oralment i per escrit en llengua catalana. Si el castellà era la llengua materna i corrent del rei, el català era la llengua d'estat preferida a la Corona d'Aragó, i el napolità, la pròpia del país. Però, això sí, quan hi arribava alguna ambaixada borgonyona, potser hom procurava afalagar els nouvinguts en un francés rudimentari, aprés de llibres de cavalleries. La llengua d'ö̈l havia esdevingut segles abans la lingua franca de la cavalleria europea i dels mercaders que navegaven per la Mediterrània. ${ }^{3}$ Aquesta era, si fa no fa, la realitat idiomàtica — plural, poliglota— de la cort napolitana d'Alfons el Magnànim.

La situació esdevé més complexa encara si considerem la presència de sicilians, que portaven llur idioma fins i tot a les planes de la Cancelleria — per tradició administrativa pròpia—; colònies mercantils de florentins, genovesos, llombards i venecians; una varietat d'accents catalans, si atenem ara a la diversa procedència del personal estranger; alguns parlants d'aragonés, idioma com més anava més castellanitzat; una acadèmia de presumptuosos humanistes, que debatien oralment i per escrit en un llatí purista i ornamental, i que menyspreaven la gramàtica macarrònica de notaris i predicadors; una petita colònia arabòfona a la cort, la de l'ambaixada permanent de Tunis i els enquadernadors de la biblioteca... Això, sense comptar amb el fet que alguns escrivans de la Cancelleria i cortesans en general manifestaven una regular competència idiomàtica per a comunicar-se en dues, tres $\mathrm{o}$, fins i tot, quatre llengües.

Fet balanç d'aquesta varietat, es pot parlar amb tota naturalitat de la cort reial com un col-lectiu dinàmic, plurilingüe i poliglot, on eren rebudes amb simpatia cançonetes "de quatre lengatges» (castellà, català, francés, napolità) com les que cantava en llaor del rei el poeta Carvajal (Compagna \& Vozzo 1993: 166). Tant el compositor castellà d'aquestes cançons amb regust popular, com els seus oients —-majoritàriament catalanòfons- de la cort alfonsina de Nàpols, entenien tots quatre llenguatges. En podien parlar dos o tres i, segurament, comprenien també el recitat d'obres escrites en un sisé (el toscà literari de Boccaccio) o en un seté llenguatge (el sicilià cancelleresc).

En l'entorn dinàmic i elitista dels cavallers i servidors del rei Alfons, doncs, es feien servir diferents llengües romàniques, molt "pròximes» i emparentades: castellà, aragonés, català, toscà, napolità, sicilià, francés... Molts cortesans eren capaços

2.Napoletano misto de toscano era, doncs, l'expressió completa d'allò que es volia definir, per distanciament respecte del napoletano puro i del toscano puro. També se'n deia napoletano illustre (Compagna 2001: 1353-1354).

3. Recordem, a tot això, que entre el I436 i el I442 la llengua di dominazione de la cort napolitana, ocupada pels Anjou, havia sigut el francés. 
Abel Soler

El català $i$ altres llengües en concurrència a la cort $i$

a la cancelleria napolitanes d'Alfons el Magnànim (I443-I458)

d'expressar-se alternativament en castellà, català i napoletano misto: l'esmentada versió cortesa i toscaneggiante de l'idioma local. Hi era corrent el sesquilingüisme, és a dir, la capacitat de parlar i de comprendre una segona llengua de manera suficient per a comunicar-se amb un nadiu, sense que calguera dominar-la completament. El fenomen, com és sabut, era corrent a la Mediterrània llatina durant la baixa edat mitjana i el Renaixement. La proximitat gramatical i lèxica de les llengües romàniques — sobretot en els segles medievals— afavoria la promiscuïtat idiomàtica.

Per aquesta raó, i deixant al marge algunes generalitzacions enciclopèdiques en ús, que retraten un rei que parla «només» en castellà i una cort "catalana» de Nàpols, s'imposa la necessitat d'acceptar que la ciutat i la cort napolitana del segle xv foren — com ja havien sigut en temps dels Anjou — un centre de concurrència de persones acomodades en petites comunitats lingüístiques (els mercaders florentins, els de la Rua Catalana, etc.), però capaces d'entendre's entre elles $\mathrm{i}$, en algun cas, interessades a parlar en més d'una o dues llengües. Caldria, doncs, revisar les fonts i introduir matisos que ajuden a entendre millor la situació de llengües en contacte que es produí al Nàpols dels primers monarques d'Aragona: Alfons I el Magnànim i Ferran I, dit il Vecchio.

\section{LA LLENGUA DEL REI I LES ALTRES LLENGÜES DE LA CORT}

El rei don Alfonso, criat en infantesa a la cort de Castella, no entrà en contacte amb la llengua catalana fins als i6 anys d'edat. Fou llavors quan s'envoltà a Barcelona d'una cort o família de cavallers i servidors castellans, aragonesos i, sobretot, catalànics. La presa de contacte tardana amb el català justifica que fera servir quasi sempre el castellà per a expressar-se oralment i per escrit, malgrat estar voltat de súbdits catalanoparlants. València, on tenia establida la cort Alfons abans d'anar-se'n a Itàlia, era una ciutat de tradicional immigració castellana i aragonesa, on l'espanyol —sobretot, en la variant dialectal baixaragonesa o "xurra»— formava part del paisatge sonor urbà. A més a més, el Palau del Real de València, pel I422, serví de refugi a desenes de famílies de l'aristocràcia castellana afectades per la dissort del partit dels «infants d'Aragó». Pot dir-se així que, des de l'inici del seu regnat, la cort del Magnànim fou una cort bilingüe, molt més del que ho havien estat les corts catalanoaragoneses dels seus predecessors en el tron, els sobirans del casal autòcton de Barcelona. ${ }^{4}$

4. El bilingüisme catalanoaragonés de la família reial era normal durant els segles XIII-XIV. Vegeu Colón (1989: 24I-25I). 
Abel Soler

El català $i$ altres llengües en concurrència a la cort $i$ a la cancelleria napolitanes d'Alfons el Magnànim (1443-I458)

Quan aquell monarca hispanòfon i els seus curials catalani s'embarcaren en l'empresa mediterrània, es trobaren immersos en una nova realitat sociolingüística: primerament, a la cort de Sicília, i seguidament a Gaeta i Nàpols. Afirma Benedetto Croce que el rei Alfons «non imparò mai bene l'italiano, e si serviva d'ordinario della lingua spagnuola (del castigliano piuttosto che del catalano, come figliuolo di principe castigliano ed educato alla corte di Enrico III)»(Croce 1917: 34-35). ${ }^{5}$ Una font coetània, el De vita beata de Juan de Lucena (Roma, I463), sembla exagerar la pretesa alteritat del rei respecte de la llengua del reialme partenopeu: «Alfonso de Aragonia, rey en Italia, viéndose defectuoso con gentes extrañas, [es véu obligat a] haber de fablar por trujamanes» (Cappelli 2002: I30). Potser que durant els primers anys recorreguera a intèrprets o torsimanys, però la naturalesa romànica i cognada del castellà, el català i els dialectes italians afavoriria, sens dubte, la perfecta comprensió per part del sobirà de la llengua dels seus súbdits italians, al cap de pocs anys.

Croce justifica que la lírica de la cort de Nàpols fóra bàsicament castellana, «e solo per piccola parte catalana», pel fet que Alfons, "figlio di principe castigliano, educato egli stesso in Castiglia, era piuttosto castigliano che catalano" (Croce I9I7: 44-45). En les corts celebrades al convent de Sant Domènec de Barcelona, el 22 de setembre del I4I6, acabat d'inaugurar el regnat, "don Alfonso" s'adreçà a l'auditori en castellà. Conscient, però, del malestar que havia causat aquesta mancança de sensibilitat idiomàtica, el parlament de les corts catalanes de Sant Cugat (4 de maig del I4I9) el pronuncià en català, just abans d'escoltar el discurs de resposta en llatí que havia preparat l'abat del monestir de Montserrat (Ametller I903-I904: III, II8-II9). A partir d'aleshores, quan Alfons $V$ d'Aragó s'adreçava a institucions o a súbdits catalànics, procurava complaure'ls usant la llengua catalana, tant per escrit com oralment. Tanmateix, i segons els testimonis italians de l'època, "la maestà del segnor re parla sempre spagnuolo.» ${ }^{6}$ Pot dir-se, en conseqüència, que el rei d'Aragó i Nàpols, Alfons el Magnànim, feia gala d'un bilingüisme passiu: parlava quasi sempre en castellà en el registre oral, però s'expressava ocasionalment — quan convenia o li plaïa— en català.

L'historiador Alan Ryder, excel-lent coneixedor del personatge reial, la seua cort i la documentació del regnat, és més precís i menys seduït pel tòpic que Croce, quan escriu que el Magnànim (1992 [1990]: 385-386)...

5. Aquesta caracterització no assoleix la contundència ideològica de l'espanyolista ultraconservador Elías de Tejada (1958: 19-20), quan assegura que Alfons parlava sempre en castellà i que «en los momentos cruciales fue estrictamente un español tallado en la recia madera de Castilla.»

6. Citat per Rubió (2004: 6I [1930: 3I]).

Caplletra 65 (Tardor, 2018), pp. 43-67 
Abel Soler

El català $i$ altres llengües en concurrència a la cort $i$

a la cancelleria napolitanes d'Alfons el Magnànim (1443-I458)

\begin{abstract}
...dominaba el italiano, al igual que el catalán y el latín, pero nunca se arriesgó a hacer ninguna declaración oficial, como por ejemplo en la réplica a un embajador, si no era en su castellano nativo, que manejaba con gran elegancia. Cuando Manetti, el embajador florentino, le preguntó al respecto, le contestó que un rey debía expresarse con claridad y fluidez, por lo cual él había de usar únicamente su lengua materna.
\end{abstract}

La mateixa situació es donava en el registre escrit: quan el rei adreçava una carta autògrafa, la dictava en castellà; sobretot si tractava d'afers familiars. Això no lleva que hi haja moltes missives, remeses a la seua muller, la reina Maria, o al seu germà Joan, ambdós castellanoparlants, però governadors d'estats catalanòfons, redactades en català per secretaris de la Cancelleria i signades després pel rei (Colón Domènech 2003: I97, n. I8). És a dir, que la llengua de govern —el català — i la llengua de família —el castellà- eren naturalment compatibles i intercanviables, sense norma ni criteri clar o prefixat, en les comunicacions epistolars de caràcter particular de cals Trastàmara. ${ }^{7}$ I això és perquè el caràcter familiar del castellà entre els primers Trastàmara, amb cort normalment emplaçada a València, un país catalanòfon...

...no modificà el caràcter «oficial» de la llengua autòctona. És possible que alguns literats, per complaure els sobirans, s'esmerçassen en la fabricació d'algunes composicions en castellà, però eren esforços individuals per lluir-se i en res no afectà la continuïtat del valencià en l'administració i en tots els órdens de la vida diària. És més, sabem que el mateix Ferran [el] d'Antequera hagué de recórrer el I4Is a l'alcaid de València perquè li traduís al 'romanç cathalán' una carta en àrab del rei de Granada (Colón 2003: 197).

És probable que, si el rei haguera continuat residint a València, els usos orals i escrits haurien sigut predominantment catalans. Sols cal fer una ullada a la biblioteca de la reina Maria, castellana de criança, però lloctinent de Catalunya, per a comprovar quina mena de lectures solia compartir amb els oients de la cort: el 86\% (63 llibres d'un total de 73 títols en llengua vulgar o romanç) en català; el IO\% en castellà (7 volums), i la resta en francés (Rodrigo 20I2: 490-49I).

Amb la translació de la seu de govern a Nàpols, el relatiu aïllament de la cort d'Alfons respecte del poble italòfon, afavoriria el fet que el rei continuara parlant en castellà i els seus curials, majoritàriament en català. El valencià Llop d'Espejo, en la seua crònica, escrita en napoletano misto pels anys I468-I470, fa memòria de la parla castellana del rei: «Don Alfonso de Aragona, respondendo a una demanda fatta per li imbassaturi de Barsalona, disse: "Vossotros ganáis por despender, e los reyes despienden

7. El vell tòpic historiogràfic de l'arribada dels Trastàmara al tron, el I4I2, entesa com l'inici d'un prolongat procés de la castellanització a la Corona d'Aragó no és possible d'acord amb les recerques dels darrers anys. Vegeu González (2009: 92). 
Abel Soler

El català $i$ altres llengües en concurrència a la cort $i$ a la cancelleria napolitanes d'Alfons el Magnànim (1443-I458)

por ganar.” (Espejo 1990: 85). En contrast amb aquesta font, Vespasiano de Bisticci comenta que, havent arribat a Nàpols «certi contadini barzalonesi che avevano differenza con quegli cittadini della terra», el rei els proporcionà I.ooo ducats de provisió perquè s'allotjaren còmodament a la ciutat. Un curial que era present a l'acte gosà intervenir per a opinar que potser eren massa diners... «Il re, per mostrare a quello suo la sua ignoranza, parlò in catalano, e si gli disse: "E' sono pochi mille ducati; datene loro mille cinquecento!” (Da Bisticci I859: 55). El biògraf emfatitza l'elecció pel monarca del català com a llengua d'interlocució en aquesta ocasió; com si es tractara d'una mena de deferència envers els pagesos «barcelonins», per tal que aquests entengueren millor, en la llengua del llur país, la magnanimitat del gest del sobirà.

Una anècdota similar, que testimonia el bilingüisme ocasional —i oportunista, segons que es mire- del rei Alfons V d'Aragó és la protagonitzada pel mercader perpinyanés Joan Traginer. Alfons li devia 4.000 ducats des de feia temps. Indignat per les promeses incomplides, el prestador accedí tot decidit a la cambra del monarca a reclamar-li personalment el deute. Caminava tot irat, amenaçant amb improperis:

\footnotetext{
«Io ve cavarrò le fecate del corpo!», parlando in catalano, perché questo è loro parlari. Et dicto benigno Re, fengiendo de non intendere, et per dare tempo et spasso all'ira, se voltò con uno viso allegro alli soi camareri dicendo nel suo [parlari]: «Ché dize, ché dize este mercante?»
}

Armat de paciència, el rei simulava no entendre els insults en català, abans que encolerir-se i contestar amb ira règia a l'alterat financer (Espejo I990: 86).

De vegades, els testimonis de contemporanis italians es presten a confusió, ja que es refereixen indefinidament al castellà com a catalano o al català com a spagnuolo. Loise da Rosa, redactor d'unes extenses memòries en dialecte napolità, hi insereix algunes frases al·loglotes, en català i castellà. Recorda, per exemple, la vegada en què la reina Joana II féu una petició incòmoda al rei Alfons. Aquest no la pogué defugir i "disse in catalano: "mas chiere" (De Rosa I998: II, 564). És directe també un testimoni de l'ambaixador milanés a Nàpols, Antonio da Trezzo, en un despatx remés al duc Francesco Sforza el I6 de febrer del I458. Diu que, esperant ell que Alfons dictara una lletra de resposta per a Sforza, el monarca...

...se voltò verso messer Martorello [el secretari Francesc Martorell] et alcuni del Consiglio che gli stavano da canto, a li quali, in suo ydioma et cum viso assay turbato, disse: «Questi traditori cercano metere inimicità fra el duch de Milan et mi, ma veramente mai lo potrano fare, perché cognosco que lo fano per desplaere che hanno de nostra amicitia, la quale se conserverà, ancora che li pese, che io già cognosco loro pratiche» (Senatore 1997: 603, doc. 233). 
Abel Soler

El català $i$ altres llengües en concurrència a la cort $i$

a la cancelleria napolitanes d'Alfons el Magnànim (I443-I458)

La teatralització victimista que improvisa el rei davant l'ambaixador milanés, ignorem si la féu en idioma castellà o en català. En qualsevol cas, l'ambaixador sembla voler comunicar al duc que el rei bonegà en català, és a dir, en la llengua dels destinataris de la reprovació. El català que parlaria com a segona llengua el rei seria, lògicament, el dialectal de la ciutat de València, on havia residit tants anys, i d'on procedien Martorell, Olzina i tants altres secretaris i curials del Nàpols alfonsí. I el mateix es pot dir del seu fill i successor, Ferran I de Nàpols, nat i criat a la mateixa València.

Interessantés, per a continuar amb aquesta casuística sobre la parla règia, la relació d'una visita que l'ambaixador florentí Gianozzo Manetti efectuà al Magnànim quan aquest es trobava a Foggia. La intenció del toscà era obtenir del sobirà la devolució d'un gran botí de mercaderies que havia sigut comissat a uns mercaders florentins. El rei escoltà la súplica del cèlebre humanista en presència del secretari Francesc Martorell, a qui ordenà Alfons — parlant en català — que redactara una cèdula ordenant la devolució d'aquella roba i la lliurara a Manetti (Da Bisticci I862: 92-94):

Andandone poi con messer Martorello (avendo messer Giannozzo preso la licenzia dalla maestà del Re) per la lettera, messer Martorello l'arebbe voluto aviluppare. Disse a messer Giannozzo: «La maestà del Re parla catelano. Non credo che la vostra magnificenza l'abbi bene inteso: la lettera dice iscriva che si soprasegga e non si seguiti più oltre.» Messer Giannozzo se gli volse e dissegli: «Io intendo molto bene el catelano e spagniuolo! La sua maestà disse che voleva che la lettera dicesse che liberamente fusse restituito ogni cosa: così le cose vendute, come le non vendute. Se voi volete fare como egli ha commesso, in nome di Dio; se voi non la volete fare, se fusse più di notte che non è, io tornerò alla sua maestà a dirgli che voi non la volete fare come egli ha commesso.»

És obvi que la proximitat idiomàtica entre les llengües romàniques no sols propiciava els intercanvis comercials per la Mediterrània, sinó que afavoria, així mateix, les relacions polítiques i diplomàtiques. I, si el rei de la Corona d'Aragó no havia aprés mai a parlar correctament ni a escriure en català o en italià, és senzillament perquè no ho necessitava. L'efectivitat comunicativa era suficient a partir del moment en què hom dominava els rudiments gramaticals i un lèxic bàsic en l'altra llengua.

La correspondència personal del rei, així com altres escrits que se li atribueixen, es redactaven comunament en espanyol. Comenta el Panormita, en el De dictis et factis (I455), que el rei Alfons «adeoque Hispanos coterraneos suos amasse et respexisse, ut epistolas Senecae ex latino in sermonem hispanum verterit, quo divini illius libri cognitio etiam litterarum rudes non pateret.» Jordi de Centelles traduí apropiadament el text: «Hi tant amava los seus vassalls de Spanya, que les epístoles de Sèneca en lengua castellana los transfferí e tresladà perquè la notícia de aquell libre divinal aribàs als hòmens lechs e ignorans» (Beccadelli 1990: 194-195). Segurament, es tractava d'un dels 
Abel Soler

El català $i$ altres llengües en concurrència a la cort $i$ a la cancelleria napolitanes d'Alfons el Magnànim (1443-I458)

exercicis pràctics per a l'aprenentatge i la millora de la gramàtica llatina, aconsellats al rei pel seu preceptor humanista. ${ }^{8}$

Sembla també que les lectures juvenils de llibres francesos — recomanables a qualsevol noble o príncep europeu del I400, independentment de quin fóra el seu idioma matern - haurien capacitat Alfons per mantenir una conversa en dit idioma. En aquest sentit, l'elevat percentatge d'obres franceses en els inventaris bibliogràfics del I4I2 i I4I7 és significatiu del paper de romanç elegant de cort i de cultura que, per antonomàsia, s'atribuïa llavors al francés. És sabut també que el futur marqués de Santillana («don Enyego Lòpeç de Mendoça», en la documentació catalana), gran amic i company de joventut d'Alfons quan era príncep, llegia amb normalitat en francés. Essent encara hereu del tron, Alfons demanà a sa tia Blanca de Sicília (27 de juny del I4I3) que li enviara «una bella Bíblia en lengatge francés, perquè, com nós desijem molt haver per nostre plaer la dita Bíblia» (Toscano 2006: I3-I4). La literatura vulgar d'aleshores (Faits de romains, novel-les de cavalleries, traduccions de Boeci o sant Agustí, etc.) era molt més facil de trobar i adquirir en francés que en qualsevol altra llengua.

\section{UNA DUALITAT PERCEPTIBLE A OÏDES D'ITALIANS: CATALANI ET HISPANI}

Si la llengua habitual en què s'expressava el rei de Nàpols era, com s'ha vist, el castellà, el romanç usual de la cort i els cortesans, de la Cancelleria i el funcionariat de govern, de les cuines i cavallerisses de Castel Capuano i Castel Nuovo, era el català. Per bé que cal tenir en compte la promiscuïtat lingüística connatural a un col-lectiu humà de caràcter internacional, on hi havia caçadors portuguesos, falconers vinguts de Polònia, algun músic flamenc, esclaus tàrtars i subsaharians, etc. Amb tot, el pes lingüístic de la colònia curial i governamental, constituïda majoritàriament per valencians, catalans i mallorquins, feia del català la llengua de govern, administració i cortesia.

8. Exercicis que començaria a realitzar segurament pel I433, estant a Messina, quan encarregà el rei la compra d'un «Sèneca en romanç», suposadament en romanç italià. Vegeu Petrucci (201I: 444-445).

9. La cuina i la gastronomia venien de l'altra banda de la mar. Així, per exemple, pels anys I437-I447, governaven la cuina un saforenc, "Pere de Gandia, coch del senyor rey»; un comprador català, Jaume Amigó, i un sotscomprador d'aliments de Xàtiva, Gabriel Davó. Vegeu Mazzoleni (I957: II7); Igual \& Navarro (I994: 85), que documenten el cuiner Pere de Gandia, i Senatore (2012: I54). Ja en temps del rei Ferran, es redactà un conegut llibre de cuina amb 223 receptes: Libre de doctrina per a ben servir de tallar e de l'art de coch, ço és, de qualsevol manera de potatges e salses; compost per lo diligent mestre Robert, coch del serenissimo senyor do Ferrando, rey de Nàpols. Vegeu Nadal \& Prats (I993 [Ia ed. 1982]: III-II2) i Robert (I982). 
Abel Soler

El català $i$ altres llengües en concurrència a la cort $i$

a la cancelleria napolitanes d'Alfons el Magnànim (I443-I458)

En qualsevol cas, la concurrència del castellà com a "segona llengua» es posava de manifest quan es congregaven al voltant del monarca els castellans - nobles i poetes de cançoner- que l'acompanyaren a la conquesta de Nàpols i a la campanya toscana. Un tercer i un quart idioma en concurrència eren, respectivament, el napoletano illustre dels prínceps i barons napolitans, ${ }^{10} \mathrm{i}$ el llatí depurat que els intel.lectuals humanistes exhibien, en cercles reduïts, com la màxima expressió de refinament cultural. ${ }^{11}$

Caldrà evitar, en tot cas, qualsevol simplificació que incidisca en el tòpic, tan amanit, de les quatre llengües literàries (català, llatí, castellà i italià) ${ }^{12} \mathrm{o}$ de les dues presumptes comunitats de parla (catalans i italians) del Nàpols alfonsí. Seria més propi d'un enfocament sociolingüístic ben contextualitzat en el segle xv, observar i discernir el posicionament o l'especialització qualitativa de cada llengua en les activitats pròpies de la cort (el pes del castellà en la lírica, per exemple; el del català, en l'administració); la competència pragmàtica o acomodatícia que exhibien no sols el rei, sinó també molts altres individus bilingües o trilingües; la versatilitat dels parlants sesquilingües, capaços de comunicar-se oralment o bàsicament en llengües romàniques afins a la pròpia, però de les quals desconeixien la gramàtica, $\mathrm{i}$, en fi, els fenòmens - lògicament explicables - d'alternança de codis idiomàtics (code-switching) ${ }^{13}$ que afectaven tant l'ambient col-loquial de la cort poliglota com el plurilingüe registre documental de la Cancelleria (Nadal \& Prats 1993: 87; Venetz 2009, 2013a, 2013b).

Per posar-ne alguns casos: enfront de la figura del rei, un monolingüe castellà amb competència lingüística per expressar-se en català, tindríem la figura del príncep Ferran, monolingüe català criat a València, però amb una bàsica competència oral $\mathrm{i}$ escrita en castellà i italià. $\mathrm{O}$ la del preceptor i secretari d'aquest, Pasqual Dias Garlon, valencià de família aragonesa, i trilingüe productiu: capaç d'expressar-se tant en castellà com en català o italià amb perfecta correcció. Fullejant els Dispacci sforzeschi (lletres de Nàpols arxivades a Milà), descobrim també que els personatges cultes de la cort, com ara el capellà reial i conseller Pere de Vila-rasa o el gran camarlenc Enyego

IO. En el registre escrit s'usava una koiné supradialectal meridional, enriquida amb fórmules toscanes i calcs sintàctics del llatí (Compagna 200I: 1353-1354).

II. L'humanista i papa Piccolomini (I998: 259), en la lloança que fa de les perfeccions del rei Alfons, lamenta que sols ocasionalment s'atrevira a expressar-se col-loquialment en llatí. Aquesta observació demostra que els col-loquis o debats en llatí — les exhibicions d'eloqüència, s'entén—eren una activitat quotidiana en els cenacles humanistes de les corts italianes del Quattrocento.

I2.Expressions del tipus «su cultura poética fue cuatrilingüe», en referència a la cort alfonsina de Nàpols, queden molt bé per a introduir la recerca (per exemple, en Deyermond 1979:35I-360), però no sé si contribueixen a explicar la cruilla cultural o a simplificar-la.

I3. No gaire diferents, d'altra banda, als que s'enregistren en comunitats plurilingües contemporànies. Vegeu Cortés (200I). 
Abel Soler

El català $i$ altres llengües en concurrència a la cort $i$ a la cancelleria napolitanes d'Alfons el Magnànim (1443-I458)

d'Àvalos, a qui atribuïm l'autoria de Curial e Güelfa (Soler 20I7), redactaven la seua correspondència amb italians en un toscà elegant i digne (Senatore 1997).

Remarcable és, també, l'espontaneïtat amb què l'oriolà Espejo escrigué en napolità dialectal la seua crònica (Compagna \& Vozzo 1993: 172-175). O la naturalitat amb què el barceloní Benet Garret, acabat d'arribar de Catalunya a Nàpols (I467/68), s'aficionà a compondre poemes en llengua toscana i assumí la seua nova condició de 'talianato amb el renom artístic d'Il Cariteo (Trillini 2003; Cantalupi 2015). En contrast amb això, l'administrador català Bernat Mates preferia dur els comptes de la masseria reial de la Pulla en la seua llengua materna (I452), tot i trobar-se immers en un ambient monolingüe italià. ${ }^{14}$ D'altra banda, el poeta castellà Carvajal jugava a combinar versos en català aprovençalat, castellà, francés i un napolità dialectal $\mathrm{o}$ popular: «un divertito omaggio alla componente napoletana della nobiltà di corte», en mots d'Anna Maria Compagna (Compagna \& Vozzo 1993: I63; Gargano, 200I). És per això que Martí de Riquer preferia parlar de la coexistència a la cort de Nàpols de "quatre vehicles lingüístics» —un esquema aplicable sobretot al registre escrit- que resultaven "entenedors a tot home culte»: el llatí, l'italià, el català i el castellà (Riquer I982: 2II). L’elecció del vehicle lingüístic no depenia tant de la natio, de la procedència comunitària de l'emissor, com de l'idioma del receptor i, sobretot, de l'ocasió: de les circumstàncies subjectives i objectives de l'acte comunicatiu.

Pel que fa a la caracterització col-lectiva del personal resident a la cort, cal tenir en compte que, al voltant del rei Alfons d'Aragó, entre «officials, domèstichs e cavallers de la casa del senyor rey», es comptaven unes 340 persones quan emprengué la conquesta de Nàpols. ${ }^{15}$ La xifra augmentà després molt, però continuà sent lleugerament inferior a les de les grans corts o cases europees. Els reis de França i els d'Anglaterra congregaven uns 800 cortesans al seu voltant (Guenée 1985: 87). En qualsevol cas, els centenars de cortesans, cavallers en servei d'armes, escrivans, criats, mercaders catalànics, etc., que freqüentaven quotidianament la cort alfonsina, representaven un col-lectiu suficientment nombrós per a afavorir el comportament "gregari» dels nouvinguts i la persistència en l'àmbit de govern de la parla catalana predominant. Ara bé, la llengua castellana era també parlada i oïda quotidianament a la cort, per la nombrosa presència de castellans, sobretot nobles i cavallers, però també caçadors, criats, cavallerissos, etc. S'explica així la descripció dual — del tipus catalani et

I4. Amb inevitables italianismes, com és lògic. Vegeu Compagna (2002).

I5. Vegeu, amb algunes discrepàncies numèriques, les xifres que aporten Sáiz (2008), Igual \& Navarro (1994: 64) i Navarro (2009: 174-175).

Caplletra 65 (Tardor, 2018), pp. 43-67 
Abel Soler

El català $i$ altres llengües en concurrència a la cort $i$

a la cancelleria napolitanes d'Alfons el Magnànim (1443-I458)

hispani-que solen fer les cròniques coetànies del collectiu de guerrers i servidors que acompanyava per Itàlia el Re di Raona.

$\mathrm{La}$ — diguem-ne- «colònia» curial, els centenars de dependents i pensionats de la cort que cobraven per distintes comeses i prebendes, eren per al rei nuestros criados, familiares nostri o familiares et alumnos meos en els escrits de la Cancelleria Reial; alumni, en traducció llatina del Panormita; creati catalani, per al poble napolità, que no trobava diferència entre castellans i catalans; hispani en la biografia del príncep Ferran del Panormita (I469), i ispani també en l'obra de l'humanista Pontano, que escriu així mateix en el regnat de Ferran I de Trastàmara (Senatore 2000: 255; 200I: 280). I és que, durant la segona meitat del segle Xv, el gentilici catalano, usat a Itàlia des de feia segles per a definir els súbdits del rei d'Aragó, començà a cedir terreny i a desaparéixer, en benefici de vocables com ispano o spagnuolo, en consonància amb la recomposició política de la Hispania antiga, assajada pels Reis Catòlics.

Aquests gentilicis i expressions — caracteritzadores d'una minoria estrangera dominant, no integrada en el cos social napolità — s'han d'entendre en un sentit lax o estricte segons el context documental. De fet, conceptes com la família o la casa del rei (la domus regia) s'empraven a manera de termes més restrictius que la cort en general. El cercle més pròxim al rei era el de la clientela militar (Sáiz 2009: I22):

\begin{abstract}
...nobles con cargos domésticos en la corte regia (camarlenc, majordom, coper, boteller, cambrer, uixer d'armes, armer, alguzir, cavalleris, cavaller o escuder de casa, patge, etc.) y los titulados como de la casa del senyor rey, equiparable a ser de la família del senyor rey, quienes debían servir al monarca en tiempos de guerra y aportar monturas militares (cavalls, cossers) en su itinerante presencia en la domus regia.
\end{abstract}

Els mateixos nobles eren condecorats amb uns títols honorífics que, en la majoria dels casos, havien perdut ja el sentit de ser: majordom, conestable, senescal, mestre portolà de Sicília, uixer d'armes, etc. Una desena de grans oficials àulics, els nobles o cavallers de la cambra del rei, solien acompanyar a taula i en hores de lleure la persona reial. Els hi acompanyaven alguns prelats i teòlegs, i un equip burocràtic constituït per una vintena de cancellers, secretaris i jurisperits. ${ }^{16}$

Els oficis i les dedicacions de cadascun, a més, donen idea d'una gran promiscuïtat: un falconer o un cap dels munteros (caçadors que duien gossos) podia participar en una ambaixada a Borgonya. Un bisbe amb estudis de jurisprudència era apte per a exercir la dignitat de canceller. Un escrivà ajudant de la biblioteca, si sabia idiomes,

I6. Per a un retrat col-lectiu i un seguiment individuals dels cortesans napolitans del rei d'Aragó, vegeu Chilà (20I4), i també el primer volum de Soler (20I7 [20I6]). 
Abel Soler

El català $i$ altres llengües en concurrència a la cort $i$ a la cancelleria napolitanes d'Alfons el Magnànim (1443-I458)

podia ser nomenat cavaller i incorporar-se al cos diplomàtic. Un cavaller amb coneixements de comptabilitat i gestió financera resultava idoni per a exercir el càrrec de tresorer general. I així, totes les combinacions que hom creia versemblants i raonables.

Tot i el predomini quantitatiu i qualitatiu del català com a llengua preferent de cort i d'estat — exèrcit, Cancelleria, Tresoreria, escrivans, bibliotecaris, etc.—, no hem de menysprear l'important contingent de castellanoparlants que poblaven la cort, en especial els d'alt rang; com, de fet, el solien tenir en compte els cronistes italians contemporanis. Acostumats en els segles XIII-XIV a parlar genèricament de catalani per a definir tots els súbdits de la Corona d'Aragó, ara es veien obligats a precisar, quan ho trobaven oportú, aquesta dualitat "nacional» dels estrangers nouvinguts, reflectida per una dicotomia lingüística. Així les coses, en la crònica napolitana coneguda com els Diurnali del duca di Monteleone, es parla de l'arribada a Nàpols, el 6 de setembre del I420, d'un estol del rei d'Aragó amb I2 galeres i 5 galiotes plenes d'homes d'armes, "tutti de Catalani et Spagnoli», en un temps en què la Spagna era un corònim emprat sovint per a designar la Corona de Castella (Pignatelli I958: I04).

Vist de manera distinta, el poeta Angelo Galli, natural d'Urbino, en una cançó en honor de Lucrezia d'Alagno (setembre del I45I), al.ludeix al rei victoriós que havia vingut a Itàlia "con pochi Ragonesi e pochi Ispani» (Nonni I998: I72-I73). Se sobreentén que els «aragonesos» serien els catalanoparlants del rei d'Aragona i els hispans, els castellanoparlants, inclosos els aragonesos pròpiament dits, que s'expressaven en la llengua dels «hispans» o castellans. De fet, en temps del Magnànim, el procés de castellanització lingüística d'Aragó era molt avançat. La llengua aragonesa s'havia diluït en els registres cancellerescos en el segle Xv. La documentació destinada al regne privatiu d'Aragó presentava — com adverteix Martí de Riquer- «més solucions fonètiques i morfològiques castellanes, i els escriptors nascuts al regne d'Aragó ja redacten en una modalitat gairebé totalment castellana.» El príncep Carles de Viana, per exemple, «escriu en pur castellà» (Riquer I982: 2II-2I2).

Pel que fa als italians, el tercer element nacional integrant de les tropes - $\mathrm{i}$, en menor manera, de l'aparell administratiu — del rei Alfons, les fonts no solen tenir-los en compte. Potser els obvien per ser naturals del país, o no els tenen en consideració per la seua relativa marginació de les altes dignitats de la cort. I perquè els grans barons napolitans tenien corts pròpies. Per exemple, el príncep de Tàrent, gran afavoridor de la causa aragonesa, comandava un gran exèrcit propi, finançat amb els seus ingressos feudals, i gaudia d'una cort privativa i regia, amb una complexa administració burocràtica — cent per cent napolitana— per als seus estats (Squitieri 1939). 
Abel Soler

El català $i$ altres llengües en concurrència a la cort $i$

a la cancelleria napolitanes d'Alfons el Magnànim (I443-I458)

\section{UN PREDOMINI CLAR DE CAVALLERS I BURÒCRATES VALENCIANS}

Un altre aspecte d'interés, ja que afecta la majoria catalanòfona de la cort, és el d'observar la procedència geogràfica o geodialectal dels immigrats, en un temps en què ja començaven a refermar-se les varietats dialectals de la llengua. A partir d'una nòmina de secretaris, cancellers, escrivans, juristes, etc., Jordi Rubió observava que al voltant del Magnànim «hi havia moltes personalitats importants sorgides dels regnes de la Península [Ibèrica], i eren valencianes moltes de les més influents».

Impressions a banda, resulta difícil disposar d'estadístiques fidedignes sobre això. Només treballant amb múltiples indicadors documentals, s'obtenen impressions i dades més o menys aproximatives. Si elegim a l'atzar una cèdula del personal amb el qual el tresor reial tenia deutes pendents (agost del I443 - febrer del I444), ens adonem que hi havia 23 catalanoparlants i 2I castellanoparlants. Entre el primer grup, apareixen Io valencians, 8 catalans i 2 mallorquins; en el segon, resulta més difícil de distingir si són de Castella o d'Aragó, però sembla que hi predominen numèricament els castellans (Rubió 1990: 80). Qualitativament parlant, hom comprova de manera fefaent que els valencians ocupen llocs de responsabilitat més importants, d'acord amb la deducció de Rubió. La xifra de castellans es presenta inflada pel nombrós col-lectiu de munteros, caçadors experts, i els aragonesos ocupen castellanies, oficis ben remunerats.

Pel que fa a la composició de l'exèrcit reial, la recerca efectuada pel medievalista Jorge Sáiz (200I: 1002) ens aporta dades significatives que podrien extrapolar-se —amb una certa prudència, això sí- al conjunt de la cort, bo i considerant que els cavallers d'una o d'altra nacionalitat solien acompanyar-se de servents conterranis. Segons dades del I44I, el 73\% dels homes d'armes del rei eren italians; un 20\%, de la Corona d'Aragó, i el 7\%, de Castella. La distribució percentual de la minoria ibèrica era aproximadament la següent: 4II castellans (35\%), 362 catalans i mallorquins (30,5\%), 30I valencians $(25,5 \%)$ i IO2 aragonesos $(9 \%) .{ }^{17}$ La proporció de catalanoparlants i castellanoparlants seria, doncs, del $56 / 44 \%$, lleugerament a favor dels efectius catalanòfons.

Quan s'analitzen les dades de distribució de tropes de cavalleria que acabem d'exposar des d'una òptica qualitativa, el pes dels valencians es dispara; si més no pel que fa als responsables principals i als oficials d'aquesta clientela militar. Així, dels 43 capitans de la tropa reial de cavalleria — la base i el gros de l'exèrcit alfonsí-, i8 (un $42 \%$ ) eren valencians, I2 catalans, 7 aragonesos i 6 castellans. El 70\% dels capitans, és a dir, de les persones més acostades al rei, serien catalanòfons.

17. Per a una millor comprensió, hem reorganitzat i arredonit els percentatges oferits per Sáiz després d'haver prescindit dels «desconeguts», que representen aproximadament el $6 \%$ del total. 
Aprofundint en la mesura de les nostres possibilitats en aquestes inquisicions estadístiques (Soler 2017 [2016]), hem comprovat que, entre un col-lectiu de més de 200 cavallers, buròcrates i eclesiàstics estudiats biogràficament, els valencians representen també la majoria:

\begin{tabular}{|l|l|l|l|l|l|}
\hline \multicolumn{6}{|c|}{ Procedència dels cortesans d'Alfons el Magnànim a Itàlia (I420-I423, I432-I458) } \\
a partir d'una mostra dels 205 individus més destacats en afers de milícia, govern i cultura \\
\hline \multicolumn{1}{|c|}{ procedència } & cavallers & buròcrates & eclesiàstics & \multicolumn{2}{c|}{ total + \% } \\
\hline València & 49 & 29 & 7 & 85 & $44 \%$ \\
\hline Catalunya & 33 & I5 & I5 & 63 & $32,5 \%$ \\
\hline Aragó & I3 & 4 & 4 & $2 \mathrm{I}$ & II\% \\
\hline Mallorques & 2 & 5 & 2 & 9 & $5 \%$ \\
\hline Castella & I3 & I & I & I5 & $7,5 \%$ \\
\hline total coneguts & IIO & 54 & 29 & I93 & I0O\% \\
\hline d'origen desconegut & 3 & 7 & 2 & & \\
\hline
\end{tabular}

No estranya aquest predomini quantitatiu —encara major si haguérem inclòs matisos qualitatius: de poder, permanència a Nàpols i proximitat al rei- en una cort, com la italiana del rei d'Aragó, producte del trasllat de la cort de València. Les cròniques adverteixen, a més, que «moltes gens e grans hòmens [de València] són anats ab gran puxança (...) a Nàpols, al senyor rey» (Miralles 20II: 237).

A efectes idiomàtics, doncs, caldria introduir algun element corrector en aquestes estadístiques, en benefici del pes del dialecte català de València a la cort napolitana. Pensem, per exemple, que els cavallers i nobles aragonesos criats i educats en una cort valenciana i catalanòfona, havien fet seua la llengua catalana, tant el registre col-loquial com l'escrit. Martí de Riquer observa com Joan Ferrandis d'Íxer (Juan Fernández de Hijar) i Joan Martines de Luna (Juan Martinez de Luna), "dos cavallers aragonesos, i que mostren orgull d'ésser-ho, s' escriuen exclusivament en català», a València, pel I434 (Riquer 1968: 94). Així mateix, alguns castellans del partit dels «infantes de Aragón», criats al palau de València o habitants d'aquesta ciutat durant molts anys, s'expressaven sovint en la llengua àulica predominant, el català que havien aprés a València. Pot ser el cas d'Alfons o Alonso d'Àvalos, a qui el cortesà napolità Loise da Rosa s'adreça sovint en les seues memòries (I452) d'aquesta manera: "Dimme, o donno Alonso, "chè ·ss parès?”, a la catalana.» $\mathrm{O}$ també: "Chè ·s parès, a vós?», és a dir, "què us pareix, a vós?» (De Rosa I998: II, 517 i 652 respectivament). El mateix rei Ferran I, nat i criat a València, pels anys I458-I460 es comunicava en català, per via epistolar, amb aquest 
Abel Soler

El català $i$ altres llengües en concurrència a la cort $i$

a la cancelleria napolitanes d'Alfons el Magnànim (I443-I458)

Alfons. ${ }^{18}$ Finalment, cal tenir en compte —a afectes també de matisació numèrica i sociològica de la proporció percentual català/castellà- que prop de Castel Nuovo i del port de Nàpols hi havia una Rua Catalana i una nodrida colònia de mercaders, marins, artesans, etc., oriünds de terres de parla catalana i habituats a freqüentar els patis d'armes i les cambres del palau reial. És probable que la colònia catalanòfona «flotant» s'elevara a un màxim de 3.000 individus, per a una població urbana de 60.000 habitants (aproximadament, el $5 \%$ del cens). Una part molt important d'aquests estrangers, segons les cròniques, abandonaria Nàpols, en onades successives, a la mort d'Alfons V (I458) i en els primers anys de la guerra successòria (I459-I462).

Les dades ací manejades, doncs, ajuden a explicar el fet que el català fóra la llengua predominant de l'estat napolità i de l'administració del rei d'Aragó entre el I $436 \mathrm{i}$ el I458, i amb un accent acusadament occidental i valencià, com el que airejava en les seues pàgines l'autor de la novel.la cavalleresca Curiale Güelfa. Es pot completar l'anàlisi, pel que fa al paper rellevant dels valencians, afegint que, quan el rei Alfons dirigí l'expedició a la Toscana (I446-I448), confià el govern de Nàpols a un consell de regència constituït només per valencians: l'infant Ferran d'Aragó, hereu del tron napolità (vingut de València, com s'ha dit); el cavaller Ximén-Peres de Corella, el secretari reial Joan Olzina i el tresorer general Mateu Pujades. «No cabe duda» — conclou Sáiz- «que la hegemonía cuantitativa de la clientela militar valenciana en I44I, era un fiel reflejo del rol decisivo que los valencianos jugaban entre el personal político y financiero al servicio de Alfonso V en su empresa napolitana» (Sáiz 200I: 999).

\section{EL CATALÀ: EL ROMANÇ PREFERIT EN L'ADMINISTRACIÓ}

La pluralitat i la promiscuïtat lingüístiques inherents a una cort com la del Magnànim troben reflex en els registres documentals de la Cancelleria Reial. ${ }^{19} \mathrm{~A}$ la juxtaposició en un mateix llibre de textos en llatí, català, castellà, sicilià, i napolità i toscà cancellerescs, s'afig la barreja de llengües que presenten alguns escrits. Així, per exemple, en una lletra reial adreçada a les autoritats de Sicília, on Alfons V confirma la donació del palau palermità de la Zisa al Panormita (I3 de juliol del I455), «la salutació és escrita en llatí, la notificació en sicilià, la pragmàtica reial en català i la confirmació reial en castellà: "Esta es mi voluntad; que assí se faga"» (Nadal \& Prats 1993: 87).

I8. Tot i que amb Guevara, molt més major que Alfons, usava també el castellà. Vegeu Venetz (2013a: 4I). 19. Els del regnat que ens ocupa han sigut descrits i analitzats conjuntament per Canellas \& Torra (2000) 
Abel Soler

El català $i$ altres llengües en concurrència a la cort $i$ a la cancelleria napolitanes d'Alfons el Magnànim (1443-I458)

El trasllat i la instal-lació a Nàpols de la Cancelleria règia de la Corona d'Aragó acabà amb la tradició burocràtica local i angevina, on tot es redactava en llatí i on el romanç era exclòs dels registres. La Cancelleria d'Alfons tenia una línia de treball plurilingüe (llatí, català i aragonés) consolidada des de feia segles (Trenchs \& Aragó I983), i comptava amb un excel.lent equip de professionals poliglotes, formats a més en retòrica i gramàtica llatines (imitadors de Sèneca i altres clàssics), ${ }^{20}$ que implantaren aquest model eficient al reialme de Nàpols. $\mathrm{O}$, més aviat, el que feren fou perpetuar i continuar els vells usos catalanoaragonesos en una nova seu administrativa. ${ }^{21}$

En el mateix regnat del Magnànim s'estava verificant un sobredimensionament de l'escrivania reial. El punt de partida, de temps de Pere el Cerimoniós (segle XIv), eren dos secretaris, sis escrivans de manament, quatre escrivans de registre, un auditor i un segellador. Tanmateix, regnant Alfons $V$ es multiplicà el nombre d'escrivans i de secretaris reials. En aquest segon cas, s'arribà a un màxim de 25 secretaris, ${ }^{22}$ per haver fet el rei d'aquest càrrec una dignitat honorífica, una mena de sinecura, que concedia, entre d'altres, a alguns humanistes acollits a la cort a fi de justificar l'estipendi anual que percebien del mecenes. A banda de la Cancelleria, hi havia l'ofici de la Tresoreria General, amb una desena d'escrivans al servei del tresorer, i la Regia Camera della Sommaria, organisme financer constituït el I444 per a reorganitzar la recaptació d'impostos al regne napolità. ${ }^{23}$ Les administracions perifèriques dels regnes de la Corona funcionaven autònomament, i responien en matèria fiscal al tresorer atenent a les disposicions de les respectives corts i als manaments del sobirà.

És remarcable el fet que, tant al si de la Cancelleria Reial com de la Tresoreria, com a la resta d'organismes administratius de l'estat alfonsí, predominava netament «l'elemento catalano» (Moscati I958). La presència de buròcrates napolitans en la direcció d'aquests organismes era més aviat anecdòtica i subalterna; o nominal i honorífica, en el cas d'alguns grans barons i nobles titulars. Alfons el Magnànim, tot i arriscar-se a generar recels entre la població autòctona, ${ }^{24}$ confià les regnes de l'administració i del govern de l'estat a «familiars» seus: a la colònia de nouvinguts hispans. Era aquesta opció, en certa manera, un procediment eficaç per a compensar els fidels que s'havien esforçat durant anys acompanyant-lo de campament en campament i de guerra en

20. Que tenia bona cura de la seua formació i de la qualitat del treball. Vegeu Aragó (1982), Rubió Balaguer (I984), Ruiz (I954-I956) i Trenchs \& Canellas (1988).

2I. Compagna (200I: I355) parla de la importació d'un model administratiu multilingüe, però amb predomini del llatí i el català.

22. Segons el recompte de Trenchs \& Aragó (1983: 7I).

23. Sobre aquesta institució, vegeu Delle Donne (2012).

24. Com li advertí Borso d'Este, en el cèlebre memorial del I445 (Foucard I877).

Caplletra 65 (Tardor, 2018), pp. 43-67 
Abel Soler

El català $i$ altres llengües en concurrència a la cort $i$

a la cancelleria napolitanes d'Alfons el Magnànim (I443-I458)

guerra. L'elecció de professionals d'enllà la mar, la majoria catalanòfons, explica que el català fóra la llengua usada preferentment en l'aparell burocràtic de la cort napolitana, i que perdurara en usos oficials i administratius —en algunes àrees- fins el I480. ${ }^{25}$

El funcionament endogàmic d'aquesta administració reial, a més, explica que l'influx lingüístic de l'italià en els textos cancellerescos fóra ínfim en temps del rei Alfons. Això no obstant, és cert que, en el transcurs dels anys, augmentà progressivament el "processo di italianizzazione (...) fra gli impiegati degli uffici», els quals es mostraran més flexibles a l'hora d'incorporar vocables o modismes italians (Compagna 20or: 1362). Tot i el predomini de la documentació en llatí i en català, sovintegen els documents en castellà, sobretot en la correspondència burocràtica i diplomàtica amb Aragó, Castella, Portugal, Granada i el Marroc. Als estats del nord d'Europa (Savoia, França, Borgonya, Anglaterra...) i de la Mediterrània Oriental (Bizanci, Xipre, Armènia, el sultà de Babilònia o d'Egipte, el Gran Turc...), se'ls escriu en català; al rei de Tunis, en canvi, per raons de geografia i tradició diplomàtica, en sicilià (Compagna 20or: 1356). La Cancelleria de Sicília, deutora d'una sòlida tradició autòctona, combinava el llatí i el sicilià, o més aviat una koiné toscanitzada, però permeable a dialectalismes sicilians (Bartolotta 2007); ${ }^{26}$ amb la qual cosa, els comunicats de Nàpols amb Sicília es lliuraven també en la llengua cancelleresca sícula. Finalment, als prínceps i les repúbliques italianes, se'ls escrivia en el volgare àulic o koiné toscaneggiante de què feien ús regular les cancelleries i els cossos diplomàtics peninsulars. Es tractava d'un italià administratiu «en procés de construcció», amb influxos gramaticals de llatí, i pendent de fixar uns cànons a partir de la imitatio de la prosa volgare trescentesca, del toscà literari dels autors més distingits (Formentin 1997: 180-182).

Per als afers domèstics del regne napolità, s'emprava una variant influïda també pel toscà literari, però que es considerava més «contaminada» per dialectalismes o per girs napolitans. És el que Giovanni Brancati, en la seua traducció de les Històries naturals de Plini, dedicada a Ferran I (I473), anomenava napolità mixt: «Non ho anche curato», es justifica l'humanista calabrés en el preàmbul de l'obra, «far la medesma traduzione in altro linguagio che in lo nostro medesmo, non pur napolitano, ma misto» (Gentile 1974: I, I2; Barbato 200Ia, 200Ib). El napolità col-loquial, que encara es parla avui a la ciutat, es considerava indigne $\mathrm{i}$ innoble per a dur a terme la tasca de volgarizzamento d'un clàssic antic i prestigiós. I val a dir que el mateix Brancati,

25. Com advertia Croce (1917: 42).

26. Aquest autor documenta per a la segona meitat del segle xv un afebliment progressiu dels usos literaris del sicilià, que tanmateix conservava plena vigència en l'àmbit cancelleresc, oficial. L'influx del toscà es percebia ja des del segle xIv, sobretot en el lèxic. Tanmateix, la veritable penetració de l'italià com a llengua dominant i model lingüístic per els àmbits administratius no s'hi produirà fins al segon quart del segle Xvi. 
Abel Soler

El català $i$ altres llengües en concurrència a la cort $i$ a la cancelleria napolitanes d'Alfons el Magnànim (I443-I458)

que aconsella Ferran estudiar més llatí i deixar-se de traduccions, també considerava una profanació l'encàrrec que — vulgues no vulgues — havia dut a terme. Les versions en romanç dels clàssics grecollatins responien, òbviament, a la demanda de burgesos i prínceps lletraferits, ${ }^{27}$ però efectuar aquest volgarizzamento era considerat una baixesa entre les elits que sostenien els ideals del moviment humanista. ${ }^{28}$

No s'han efectuat estudis de quantificació estadística de la producció documental de la burocràcia napolitana en temps del Magnànim. Aquesta es caracteritzava — com s'ha vist — per un plurilingüisme pragmàtic, d'acord amb la naturalesa plurinacional i multilingüe dels estats reunits davall un mateix ceptre. Això no obstant, la impressió unànime dels historiadors i dels filòlegs és que la llengua catalana era usada en aquell àmbit $\mathrm{amb}$ abundància i preferència; que constituïa en temps d'Alfons el Magnànim — un rei castellanoparlant - la vertadera llengua d'estat: el vehicle expressiu de la identitat cultural de la Corona d'Aragó, «deçà e dellà» la mar.

El terreny dels usos lingüístics en literatura (el llatí humanístic, els poetes de cancionero castellans i aragonesos, la poesia en català, l'anecdòtica producció en toscà i en napolità, o l'extraordinària prosa catalana del Curial, amb preferències lèxiques valencianes) mereixeria, finalment, disposar d'un apartat a banda en aquest repàs — un tant impressionista - dels usos lingüístics a la cort alfonsina d'Itàlia. Tanmateix, atesa l'especial atenció que el tema requeriria, seria més raonable ajornar-ne l'exposició.

Abel Soler

Universitat de València abel.soler@uv.es

ORCID: 0000-0002-5964-543I

27. Un cas singular pot ser el de Filippo Maria Visconti, que, atesos els seus rudimentaris coneixements de llatí, impulsà a la seua cort la traducció de múltiples clàssics, duta a terme resignadament pels humanistes als quals protegia. Vegeu Decembrio (1983: 32-34).

28. Sobre aquesta traducció i les consideracions de Facio, Valla o Brancati, que es veren obligats a traduir obres per a Ferran, vegeu Bentley (I996: 84-86, II6 i I24) i Senatore \& Montuori (2009: 538). Segons Fernández (2000: 67), a Itàlia, «la traducción al volgare de los clásicos no prosperó» d'igual manera que en altres països del continent, «debido al carácter sacramental que se le otorgó al latín». 
Abel Soler

El català $i$ altres llengües en concurrència a la cort $i$

a la cancelleria napolitanes d'Alfons el Magnànim (I443-I458)

\section{REFERÈNCIES BIBLIOGRÀFIQUES}

Ametller Vinyas, J. (1903-1904) Alfonso V de Aragón en Italia y la crisis religiosa del siglo XV; obra póstuma de José Ametller y Vinyas, revisada y dada a luz por Jaime Collell, Girona, P. Torres.

Aragó, A. M. (1982) «Prenotaciones a la escritura cancilleresca de Alfonso el Magnánimo", dins IX Congresso di Storia della Corona d'Aragona (Napoli, II-IS aprile 1973), sul tema "La Corona d'Aragona e il Mediterraneo. Aspetti o problemi comuni da Alfonso il Magnanimo a Ferdinando il Cattolico (I4I6-ISI6)", II (Comunicazioni), Nàpols, Società Napoletana di Storia Patria, pp. 49-56.

Barbato, M. (200Ia) «Plinio il Vecchio volgarizzato da Landino e da Brancati», dins R. Gualdo (ed.), Le parole della scienza. Scritture e tecniche scientifiche in volgare (secoli XIII-XIV). Atti del Convegno (Lecce, I6-I8 aprile I999), Galatina, Congedo, pp. $187-227$.

— (200Ib), «Prefazione» a l'ed. de Plini el Vell, Il libro VIII del Plinio napoletano di Giovanni Brancati, Nàpols, Liguori.

Bartolotta, S. (2007) «Koiné sículo-toscanizada en los dominios de la Corona de Aragón", Espacio, tiempo, forma. Serie III. Historia medieval, 20, pp. 315-323.

BeCCADELLI, A. [Il Panormita] (I990) Dels fets e dits del gran rey Alfonso, versió catalana de J. de Centelles, ed. a cura d'E. Duran; establiment del text llatí a cura de Mariàngela Vilallonga; apèndix de J. Ruiz Calonja, Barcelona, Barcino.

Bentley, J. H. (1996) Politica e cultura nella Napoli rinascimentale, trad. de Cosima Campagnolo, Nàpols, Guida.

Canellas López, Á. (1988) Cancillería y cultura. La cultura de los escribanos y notarios de la Corona de Aragón (1344-I479), Saragossa, Cátedra Zurita / Institución Fernando el Católico.

Canellas, B. \& A. Torra (2000) Los registros de la cancillería de Alfonso el Magnánimo, Madrid, Ministerio de Educación, Cultura y Deporte / Dirección General del Libro, Archivos y Bibliotecas.

Cantalupi, C. (2015) «Il declino degli Aragonesi di Napoli nel Libro de la Methamorphosi di Benet Garret il "Cariteo"”, eHumanista/IVITRA, 7, pp. 2I-4I.

Cappelli, G. M. (2002) El humanismo romance de Juan de Lucena. Estudios sobre el "De vita felici», Bellaterra, Seminario de Literatura Medieval y Humanística / Universitat Autònoma de Barcelona.

CHILÀ, R. (20I4) Une cour à l'epreuve de la conquête: la société curiale et Naples, capitale d'Alphonse le Magnanime (I4I6-I458), tesi doctoral, Montpeller, Université Paul 
Abel Soler

El català $i$ altres llengües en concurrència a la cort $i$ a la cancelleria napolitanes d'Alfons el Magnànim (1443-I458)

Valéry / Montpellier III. [En línia: <https://tel.archives-ouvertes.fr/tel-oII44965/ file/20I4_CHILA_diff.pdf>; consulta: gener del 2016.

Compagna Perrone Capano, A. M. (200I) "L'uso del catalano a Napoli», dins

G. d'Agostino \& G. Buffardi (eds.), XVI Congresso di storia della Corona d'Aragona (Napoli-Caserta-Ischia, I8-24 settembre 1997): "La Corona d'Aragona ai tempi di Alfonso I il Magnanimo: i modelli politico-istituzionali, la circolazione degli uomini, delle idee, delle merci; gli influssi sulla società e sul costume», vol. II, Nàpols, pp. 1353-I370.

- (2002) «Catalano e italiano nei conti di una maseria regia di Puglia a metà del secolo XV", dins Raccolta di scritti in memoria di Antonio Villani, vol. I, Nàpols, Istituto Suor Orsola Benincasa, pp. 46I-47I.

Compagna Perrone Capano, A. M. \& L. Vozzo Mendia (I993) «La scelta dell'italiano tra gli scrittori iberici alla corte aragonese di Napoli: (I) Le liriche di Carvajal e Romeu Llull. (2) La Summa di Lupo de Spechio», dins Lingue e culture dell'Italia meridionale (I200-I600). Bilanci, lavori in corso, prospettive (Fisciano, Salerno, I99I), Roma, Bonacci.

Colón Domènech, G. (1989) El español y el catalán, juntos y en contraste, Barcelona, Ariel.

- (2003) «La decadència de la llengua al segle Xvı», dins De Ramon Llull al Diccionari de Fabra. Acostament lingüistic a les lletres catalanes, Barcelona, Publicacions de l'Abadia de Montserrat, pp. I89-202.

Cortés Moreno, M. (200I) «Fenómenos originados por las lenguas en contacto: cambio de código, préstamo lingüístico, bilingüismo y diglosia», Wenzao Journal, I5, pp. 295-312.

Croce, B. (I917) La Spagna nella vita italiana durante la Rinascenza, Bari, Giuseppe Laterza \& Figli.

DA Bisticci, V. (I859) Vite di uomini illustri del secolo XV, ed. a cura d'A. Bartoli, Florència, Barbera, Bianchi e Compagnia.

- (I862) Commentario della vita di messer Giannozzo Manetti, ed. a cura de B. del Nero, Torí, Unione tipografica-editrice.

Decembrio, P. C. (1983) Vita di Filippo Maria Visconti, ed. a cura d'E. Bartolini, Milà, Adelphi.

Delle Donne, R. (20I2) Burocrazia e fisco a Napoli tra XV e XVI secolo. La Camera della Sommaria e il "Repertorium alphabeticum solutionum fiscalium Regni Siciliae Cisfretanae», Florència, Firenze University Press.

De Rosa, L. (1998) Ricordi. Ed. critica del ms. ital. 9I3 de la Bibliothèque nationale de France, ed. a cura de V. Formentin, Roma, Salerno editrice. 
Abel Soler

El català $i$ altres llengües en concurrència a la cort $i$

a la cancelleria napolitanes d'Alfons el Magnànim (1443-I458)

Deyermond, A. D. (1979) «Edad Media», dins F. Rico (dir.), Historia y crítica de la literatura española, Barcelona, Crítica, Barcelona, pp. 35I-360.

Elías de Tejada, F. (1958) Nápoles hispánico, tomo I. La etapa aragonesa (I442-I503), Mardrid, Montejurra.

Espejo, Llop d' [Lupo de Spechio] (1990) Summa dei re di Napoli e di Sicilia, e dei re d'Aragona, ed. a cura d'A. M.Compagna Perrone Capano, Nàpols, Liguori.

Fernández Gallardo, L. (2000) El Humanismo renacentista: de Petrarca a Erasmo, Madrid, Arco Libros.

Formentin, V. (1995-1997) «La "crisi” linguistica del Quattrocento», dins E. Malato (dir.), Storia della letteratura italiana, volume III. In Quattrocento, Roma, Salerno editrice, pp. 159-210.

Foucard, C. (I877) «Fonti di storia di Napoli nell'Archivio di stato di Modena. Descrizione della città di Napoli e statistica del Regno nel I444", Archivio storico per le province napoletane, 2, pp. 725-757.

Gargano, A. (200I) «Aspetti della poesia di corte. Carvajal e la poesia di Napoli al tempo di Alfonso il Magnanimo», dins G. D’Agostino \& G. Buffardi (eds.), XVI Congresso di storia della Corona d'Aragona (Napoli-Caserta-Ischia, I8-24 settembre 1997): "La Corona d'Aragona ai tempi di Alfonso I il Magnanimo: i modelli politico-istituzionali, la circolazione degli uomini, delle idee, delle merci; gli influssi sulla società e sul costume», vol. II, Nàpols, pp. I443-I452.

Gentile, S., ed. (1974) Caio Plinio Secondo. La storia naturale [libri I-XI] tradotta in "napoletano misto» da Giovanni Brancati, Nàpols, 3 vol.

GonzÁlez Ollé, F. (2009) «Actitudes lingüísticas de los reyes de Aragón», dins V. Lagüéns García (ed.), "Baxar para subir». Colectánea de estudios en memoria de Tomás Buesa Oliver, Saragossa, CSIC / Institución Fernando el Católico, pp. 85-IIO.

GuenÉE, B. (1985) Occidente durante los siglos XIV y XV. Los estados, Barcelona, Labor.

Igual, D. \& G. Navarro (1994) La tesorería general y los banqueros de Alfonso V el Magnánimo, Castelló de la Plana, Sociedad Castellonense de Cultura.

Mazzoleni, J., ed. (1957) Fonti aragonesi, a cura degli archiviste napoletani. Testi e documenti di storia napoletana pubblicati dall'Accademia Pontaniana, I957-1983, serie II, vol. I. Il registro "Privilegiorum summariae» XLIII (I42I-I450). Frammenti di cedole della tesoreria di Alfonso I (I437-I454), Nàpols, Accademia Pontaniana.

Miralles, M. (20II) Crònica i dietari del capellà d'Alfons el Magnànim, ed. a cura de Mateu Rodrigo Lizondo, València, Universitat de València.

Moscati, R. (1958) «Nella burocrazia centrale d'Alfonso d'Aragona: le cariche generali», dins Miscellanea in onore di Roberto Cessi, vol. I, Roma, pp. 365-377. 
Abel Soler

El català $i$ altres llengües en concurrència a la cort $i$ a la cancelleria napolitanes d'Alfons el Magnànim (1443-I458)

Nadal, J.-M. \& M. Prats (i993 [ia ed. 1982] Història de la llengua catalana. vol. I. Dels origens al segle XV, Barcelona, Edicions 62.

Navarro Espinach, G. (2009) «Consejeros influyentes y personas de confianza en el entorno cortesano de los reyes de Aragón (siglos XIII-XV)», dins A. Sesma (coord.), La Corona de Aragón en el centro de su historia (I208-I458). "La Monarquia aragonesa y los reinos de la Corona» (Zaragoza y Monzón, I al 4 de diciembre de 2008), Saragossa, Departamento de Educación, Cultura y Deporte del Gobierno de Aragón, pp. I29-I8I.

Nonni, G. (1998) «Angelo Galli», dins Dizionario biografico degli italiani, vol. LI, Roma, Istituto dell'Enciclopedia Treccani, pp. I72-I73.

Palmieri, S. (2006) La cancelleria del Regno di Sicilia in età angioina, Nàpols, Giannini.

Petrucci, A. (20II) Libros, escrituras y bibliotecas, ed. a cura de F. M. Gimeno Blay, Salamanca, Universidad de Salamanca.

Piccolomini, E. S. [papa Pío II] (I998) La Europa de mi tiempo (I405-I458), trad. i ed. de Francisco Socas, Sevilla / Universitat de Sevilla.

Pignatelli, E. [duca di Monteleone], compil. (1958) Diurnali del Duca di Monteleone, ed. a cura de M. Manfredi, Bolonya, Zanichelli.

Riquer, M. de (I968) L'arnès del cavaller. Armes $i$ armadures catalanes medievals, Esplugues de Llobregat, Ariel.

- (I982) «Elements comuns en la cultura i l'espiritualitat del món aragonès», dins $I X$ Congresso di Storia della Corona d'Aragona (Napoli, II-IS aprile I973), sul tema "La Corona d'Aragona e il Mediterraneo. Aspetti o problemi comuni da Alfonso il Magnanimo a Ferdinando il Cattolico (I4I6-ISI6)", vol. I. Relazioni, Nàpols, Società Napoletana di Storia Patria, pp. 2II-232.

Robert, Mestre (1982) Libre del coch, ed. a cura de V. Leimgruber, Barcelona, Curial. Rodrigo Lizondo, M. (20I2) «Personalitat i cultura de Maria de Castella, reina d'Aragó", dins R. Bellveser (coord.), Dones i literatura entre l'edat mitjana i el Renaixement, vol. II, València, Institució Alfons el Magnànim, pp. 47I-526.

Rubió Balaguer, J. (1984) «Influència de la sintaxi llatina en la cancelleria catalana del segle XV», Revista de Llengua i Dret, 3, pp. 7I-76.

- (1990) Humanisme i Renaixement, Barcelona, Publicacions del'Abadia de Montserrat. Rubió Lluch, A. (2004 [1930]) Del nombre y la unidad de la lengua catalana. Discurso leido ante la Real Academia Española en la recepción pública del señor don Antonio Rubió y Lluch, el día 23 de marzo de I930, Barcelona, Àngel Ortega; reed. a cura de G. Colón Domènech, Barcelona, Institut d'Estudis Catalans.

Ruiz Calonja, J. (I954-I956) «Valor literario de los preámbulos de la cancillería real catalano-aragonesa en el siglo XV», Boletín de la Real Academia de Buenas Letras de Barcelona, 26, pp. 205-234. 
Abel Soler

El català $i$ altres llengües en concurrència a la cort $i$

a la cancelleria napolitanes d'Alfons el Magnànim (I443-I458)

Ryder, A. (1992 [1990]) Alfonso the Magnanimous, King of Aragon, Naples and Sicily (I396-I458), Nova York / Oxford, Clarendon Press / Oxford University Press; reed. com Alfonso el Magnánimo, rey de Aragón y Sicilia (I396-I458), València, Alfons el Magnànim.

Sáiz Serrano, J. (200I) «Los capitanes de Alfonso el Magnánimo en la conquista del reino de Nápoles: la caballería del ejército real de I44I», dins G. D'Agostino \& G. Buffardi (eds.), XVI Congresso di storia della Corona d'Aragona (NapoliCaserta-Ischia, I8-24 settembre 1997): "La Corona d'Aragona ai tempi di Alfonso I il Magnanimo: i modelli politico-istituzionali, la circolazione degli uomini, delle idee, delle merci; gli influssi sulla società e sul costume», vol. I, Nàpols, pp. 981-IoIo.

- (2008) Caballeros del rey. Nobleza y guerra en el reinado de Alfonso el Magnánimo, València, Universitat de València.

- (2009) «Los ejércitos del rey en la Corona de Aragón (siglos XIV-XV)», dins A. Sesma Muñoz, La Corona de Aragón en el centro de su historia (I208-I458). La Monarquia aragonesa y los reinos de la Corona (Zaragoza y Monzón, I al 4 de diciembre de 2008), Saragossa, Departamento de Educación, Cultura y Deporte del Gobierno de Aragón, pp. 97-I28.

Senatore, F., ed. (1997) Dispacci sforzeschi da Napoli. Volume I (I444-2 luglio I458), Salern, Istituto italiano per gli studi filosofici / Carlone.

— (2000), «Le ultime parole di Alfonso il Magnanimo», dins G. Rossetti \& G. Violo (eds.), Medioevo, Mezzogiorno, Mediterraneo. Studi in onore di Mario Del Treppo, vol. II, Nàpols, Liguori / GISEM, pp. 247-270.

- (200I), «Pontano e la guerra di Napoli», dins Mario Del Treppo (coord.), Condottieri e nomini d'arme nell'Italia del Rinascimento, Nàpols, GISEM / Liguori, pp. 279-309.

- (2012) «Cedole e cedole di tesoreria. Note documentarie e linguistiche sull'amministrazione aragonese nel Quattrocento", Rivista italiana di studi catalani, 2, pp. I27-I56.

Senatore, F. \& F. Montuori (2009), «Discorsi ripotati alla corte di Ferrante d'Aragona», dins G. Abbamonte, L. Miletti \& Luigi Spina (eds.), Discorsi alla prova (Atti del Quinto Colloquio italo-francese: "Discorsi pronunciati, discorsi ascoltati: contesti di eloquenza tra Grecia, Roma ed Europa» (Napoli, S. Maria di Castellabate, 2I-23 settembre 2006), Nàpols, Pubblicazioni del Dipartimento di Filologia Classica F. Arnaldi dell'Università degli Studi di Napoli Federico II / Gianni Editore, pp. 519-577. 
Abel Soler

El català $i$ altres llengües en concurrència a la cort $i$ a la cancelleria napolitanes d'Alfons el Magnànim (1443-I458)

SOLER, A. (20I7 [2016]) La cort napolitana d'Alfons el Magnànim: el context de "Curiale Güelfa», Institució Alfons el Magnànim / Institut d'Estudis Catalans /Universitat de València, València/Barcelona, 3 vol., 5138 pp.

— (2017), «Enyego d'Àvalos, autor de Curiale Güelfa?», Estudis Romànics, 39, pp. I37-I65. SQuitieri, A. (I939) «Un barone napoletano del Quattrocento: Giovanni Antonio del Balzo Orsini, principe di Taranto", Rinascenza salentina, 7, pp. I38-185.

Toscano, G. (2006) «Alfonso il Magnanimo (I396-I458). Un re bibliofilo tra cultura tardogotica e umanesimo latino", dins M. Bollati (coord.), La Divina Commedia di Alfonso d'Aragona, re di Napoli (manoscritto Yates Thompson 36, Londra, British Library), vol. I, Mòdena, Franco Cosimo Panini, pp. 13-64.

Trenchs, J. \& A.-M. Aragó (1983) Las cancillerías de la Corona de Aragón y Mallorca desde Jaime I a la muerte de Juan II, Saragossa, Cátedra Zurita / Institución Fernando el Católico.

Trenchs, J. \& A.-M. Canellas (1988) «La cultura dels escribes i notaris de la Corona d'Aragó (I344-I479)", Caplletra, 5, pp. 5-38.

Trillini, M. (2003) «Un poeta catalán en la corte de Nápoles. Reflexiones sobre la obra y la lengua de Benet Garret", Revista de lenguas y literaturas catalana, gallega y vasca, 9 ("Del Humanismo», coord. per J. Butinyà), pp. 95-II5.

Venetz, G. H. (2009) «Il Codice Aragonese (I458-I460): la distribuzione delle tre lingue, napoletana, catalana e latina», Zeitschrift für Katalanistik, 22, pp. 273-292.

- (2013a) «ll catalano nella Corte Aragonese a Napoli riflesso in documenti bilingui della cancelleria di Ferrante. Uno studio storico-sociale», Scripta. Revista internacional de literatura i cultura medieval i moderna, I, pp. 37-54.

- (2013b) «Intimità o segreto? L'uso del catalano nei documenti bilingui del Codice Aragonese (I458-I460)», dins T. Krefeld, W. Oestereicher \&V. Schwärgerl-Melchior (eds.), Reperti di plurilinguismo nell'Italia spagnola (sec. XVI-XVII), Berlín / Boston, De Gruyter, pp. 177-198. 
